\title{
Spatiotemporal Variations of Meteorological Droughts in China During 1961-2014: An Investigation Based on Multi-Threshold Identification
}

\author{
Jun $\mathrm{He}^{1,2} \cdot$ Xiaohua Yang ${ }^{2} \cdot{\text { Zhe } \mathrm{Li}^{1} \cdot \text { Xuejun Zhang }}^{1,3} \cdot$ Qiuhong Tang ${ }^{1}$
}

Published online: 18 March 2016

(c) The Author(s) 2016. This article is published with open access at Springerlink.com

\begin{abstract}
As a major agricultural country, China suffers from severe meteorological drought almost every year. Previous studies have applied a single threshold to identify the onset of drought events, which may cause problems to adequately characterize long-term patterns of droughts. This study analyzes meteorological droughts in China based on a set of daily gridded $\left(0.5^{\circ} \times 0.5^{\circ}\right)$ precipitation data from 1961 to 2014. By using a multi-threshold run theory approach to evaluate the monthly percentage of precipitation anomalies index $(P a)$, a drought events sequence was identified at each grid cell. The spatiotemporal variations of drought in China were further investigated based on statistics of the frequency, duration, severity, and intensity of all drought events. Analysis of the results show that China has five distinct meteorological drought-prone regions: the Huang-Huai-Hai Plain, Northeast China, Southwest China, South China coastal region, and Northwest China. Seasonal analysis further indicates that there are evident spatial variations in the seasonal contribution to regional drought. But overall, most contribution to annual drought events in China come from the winter. Decadal variation analysis suggests that most of China's water resource regions have undergone an increase
\end{abstract}

Qiuhong Tang

tangqh@igsnrr.ac.cn

1 Key Laboratory of Water Cycle and Related Land Surface Processes, Institute of Geographic Sciences and Natural Resources Research, Chinese Academy of Sciences, Beijing 100101, China

2 School of Environment, Beijing Normal University, Beijing 100875, China

3 University of Chinese Academy of Sciences, Beijing 100049, China in drought frequency, especially in the Liaohe, Haihe, and Yellow River basins, although drought duration and severity clearly have decreased after the 1960s.

Keywords China $\cdot$ Meteorological drought $\cdot$ Multithreshold run theory method - Spatiotemporal variations

\section{Introduction}

Drought is a major natural hazard with widespread impacts around the world. Severe drought events occurred in China over the last few decades and these events have had extensive socioeconomic impacts (Barriopedro et al. 2012). For example, North China has experienced frequent droughts since the 1990s. A severe drought in 1997 resulted in 226 days of zero flow in the lower reach of the Yellow River, which created a dry river bed $687 \mathrm{~km}$ long (Liu and Zhang 2002; Wang et al. 2011). Southwestern China has also suffered from a devastating drought event from autumn 2009 to spring 2010 during which approximately 21 million people were short of drinking water and the economic losses reached nearly USD 30 billion (Yang et al. 2012). These and earlier droughts, for example, in the 1930s, 1959-1962, and 1999-2003 (Ding 2008), highlight the drought risk in China and indicate why it is critically important to understand the spatiotemporal variability of drought.

Definitions of drought can be classified into four categories: meteorological, hydrological, agricultural, and socioeconomic drought (Wilhite and Glantz 1985; Mishra and Singh 2010). The range of drought impacts is linked to the stages of the hydrological cycle where droughts occur. Meteorological drought is a stochastic phenomenon for which exact duration and area affected cannot be predicted 
(Bayat et al. 2015). Meteorological drought is characterized as the occurrence of below-normal precipitation over a certain period of months to years in a region (China Meteorological Administration 2006). Meteorological drought is also the basis for identifying other drought types (Dracup et al. 1980; Oladipo 1985; Fleig et al. 2006). Precipitation has been commonly used for meteorological drought analysis (Santos 1983). Many studies have analyzed droughts using monthly precipitation data (Gibbs 1975; Dash et al. 2012; He et al. 2014). Other approaches analyze drought duration and intensity in relation to cumulative precipitation shortages (Chang and Kleopa 1991; Estrela et al. 2000).

Understanding the spatiotemporal patterns of meteorological drought is important for drought risk management. A large number of previous studies have examined drought variations over China (Xu et al. 2015). For example, Qian and Zhu (2001) analyzed the droughts of seven regions in China from 1880 to 1998 , and found that the aridification trend has become more serious since the 1970s in North China. Shen et al. (2007) identified three exceptional drought events that occurred over the monsoon region of China during the past five centuries: 1586-1589, 1638-1641, and 1965-1966. Wang et al. (2011) quantified drought in China based on a land surface model that simulated soil moisture during 1950-2006 and claimed that central and northeastern China had exhibited a significant drying tendency. Wu et al. (2011) found a significant increasing trend of drought frequency, particularly in North China.

For a broader spatial extent, Oh et al. (2014) analyzed drought characteristics over East Asia based on an effective drought index and found a seasonal pattern in which shortterm ( $<200$ days) droughts mainly occurred in spring and summer, whereas long-term droughts ( $>200$ days) mainly started in autumn and winter. Yu et al. (2014) calculated the standardized precipitation evapotranspiration index (SPEI) and reported that drought was becoming more severe since the late 1990s in most parts of China and that the drying area increased by $3.72 \%$ per decade. In contrast, Wang et al. (2014) concluded that there is little evidence of an increase in drought severity over China at the national scale during the 1961-2012 period. Focusing on extreme events, Zhang and Zhou (2015) reviewed drought history and predicted the occurrence of severe droughts over East Asia. They concluded that North China and Southwest China present the greatest drought frequency and longest drought duration.

Although there exists a variety of studies that focus on spatiotemporal variations of drought in China, drought events are mainly identified using a single threshold value, which may divide a prolonged drought into a number of minor droughts. For this reason, previous studies were unable to fully capture the characteristic of long-term drought events. Therefore, there are two questions generated by the traditional drought event identification process (Bonacci 1993; Sung and Chung 2014): (1) What is the best way to remove the minor droughts in an identified drought event series? Robust statistical analysis of drought characteristics may be complicated by a large number of minor drought events that are usually present in the drought event series. (2) Can seemingly unrelated drought events be merged into one drought event according to their spatiotemporal continuity? During a prolonged dry period, rainfall may exceed the drought threshold value for short periods, and a long-lasting drought may be mathematically divided into a number of minor drought events that are in fact physically interrelated. It is essential to merge these mutually related droughts rather than treat them as if they were independent of each other.

To address these issues, in this study a drought event was identified by the run threshold method, which was proposed by Yevjevich (1967) using run theory and was found more effective than the traditional single thresholdbased method for identifying drought parameters and investigating statistical properties of drought events. A run is defined as a succession of the same types of observation variables and succeeded by one or more observation variables of a different type (Dracup et al. 1980; Mishra and Singh 2010). According to the defined threshold, a drought index series is divided into two states, drought and nondrought. Many previous studies suggest that the run theory method better identifies regional drought events, especially for annual and seasonal drought as compared to the traditional method (Sen 1980; Zelenhasić and Salvai 1987; Lloyd-Hughes and Saunders 2002; Hallack-Alegria and Watkins 2007; Zhai and Feng 2008; Burke and Brown 2010; Dash et al. 2012; Nandintsetseg and Shinoda 2012). In this study, an improved run theory method containing three thresholds (drought occurrence threshold, minor drought-removing threshold, and adjacent drought-pooling threshold) is proposed. Application of a multi-threshold run methodology can effectively solve the main problems of drought identification.

The aim of this article is to analyze the spatiotemporal variations of meteorological drought in China during the past half-century (1961-2014). Drought characteristics and their variations have been investigated based on a statistical analysis that considers the frequency, duration, severity, and intensity of all the identified drought events. This study also evaluates drought variations for 10 water resource regions. The results can provide support for decisionmaking critical to Chinese drought-mitigation strategy and drought-risk management. 


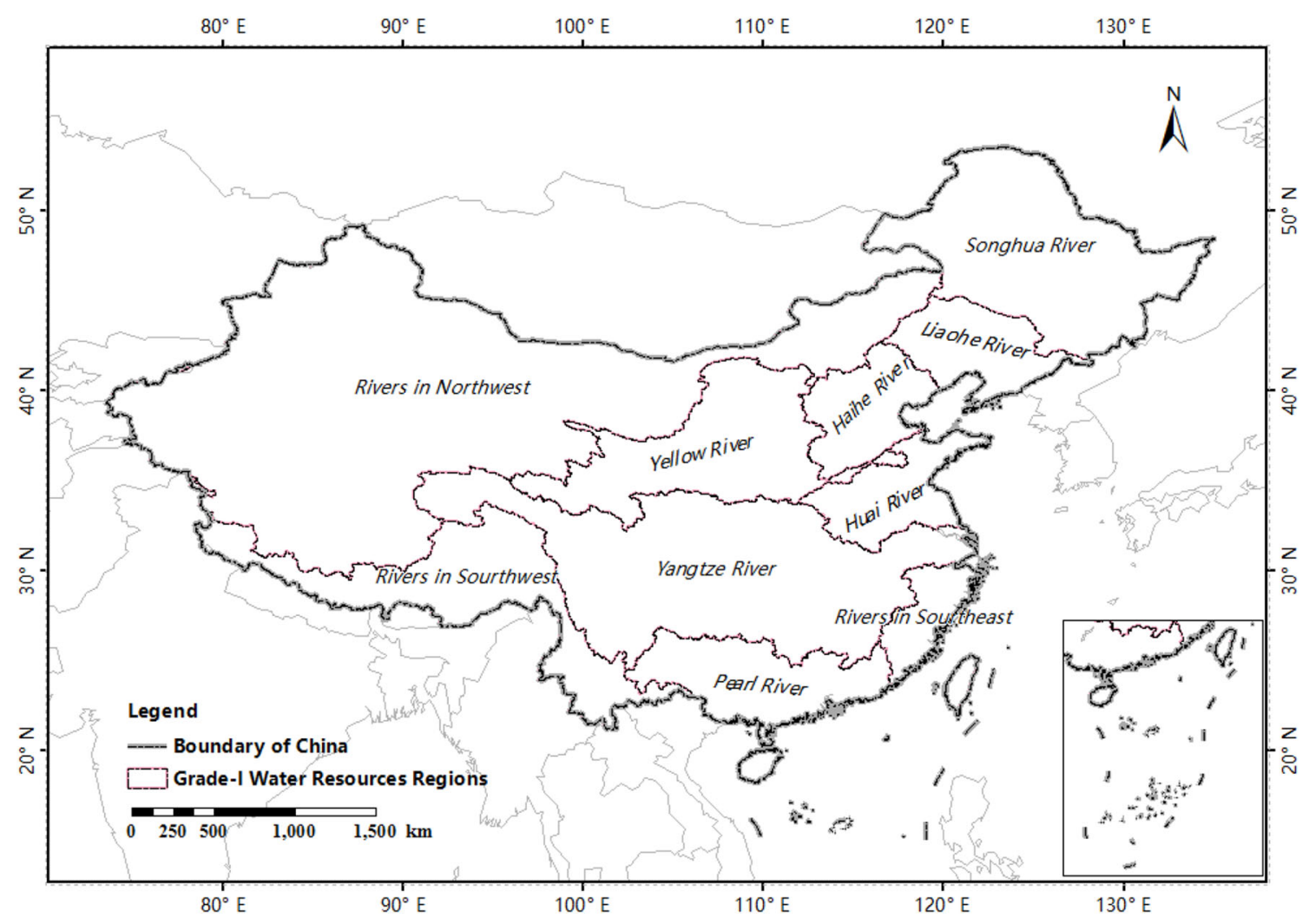

Fig. 1 Ten major water resource regions of China

\section{Study Area and Data}

China's climate shows great spatial diversity. Western China, located in the north of the Qinghai-Tibet Plateau, is a typical arid and semiarid area. In contrast, eastern China is a typical monsoon area. Drought and flooding over this region are closely related to the variability of the East Asian monsoon system, which features strong southerly winds in the summer and northerly winds in the winter (Zhang and Zhou 2015). Owing to diverse climate conditions and complicated topography influences, drought is one of the most frequent natural disasters in China and occurs with great variability at different scales. In general, drought can be viewed as a shortage of precipitation and therefore it is a direct threat to water resource management practices and plans. This article analyzes the spatiotemporal variations of meteorological drought in mainland China with special focus on the major water resource regions. Figure 1 shows the 10 major water resource regions in China, and Table 1 gives a brief summary of seven regions where data are available.

Daily gridded $\left(0.5^{\circ} \times 0.5^{\circ}\right)$ precipitation data from 1961 to 2014 were obtained from the China Meteorological Data Sharing Service System. ${ }^{1}$ These data were generated by interpolating the daily observations of over 2472

\footnotetext{
${ }^{1}$ http://cdc.nmic.cn.
}

national-level weather recording stations into $0.5^{\circ}$ regular grid based on the thin plate smooth spline method. The interpolation process has been quality-controlled by the background climatology fields. Details of the dataset are described in Wu and Gao (2013). The gridded daily precipitation was integrated into a monthly scale format for the following drought analysis.

\section{Methods}

An overview of the methodology adopted for meteorological drought spatiotemporal variations analysis in China is presented in Fig. 2. Detailed description of various components of the methodology is provided in subsequent sections.

\subsection{Drought Index}

Drought indices are invariably used as the indicator for drought identification and quantification. However, the difficulty in regional drought identification is how to select a proper drought index for a specific study region. A single consensus or empirical guiding principle in this is absent in this area (Mishra and Singh 2010; Carrão et al. 2014). Intuitively, meteorological drought mainly results from a 
Table 1 Basic facts of seven major water resource regions in China

\begin{tabular}{|c|c|c|c|c|c|c|c|}
\hline Statistical index & $\begin{array}{l}\text { Songhua } \\
\text { River }\end{array}$ & $\begin{array}{l}\text { Liaohe } \\
\text { River }\end{array}$ & $\begin{array}{l}\text { Haihe } \\
\text { River }\end{array}$ & $\begin{array}{l}\text { Yellow } \\
\text { River }\end{array}$ & $\begin{array}{l}\text { Huaihe } \\
\text { River }\end{array}$ & $\begin{array}{l}\text { Yangtze } \\
\text { River }\end{array}$ & $\begin{array}{l}\text { Pearl } \\
\text { River }\end{array}$ \\
\hline Drainage area $\left(10^{6} \mathrm{~km}^{2}\right)$ & 5.57 & 2.29 & 2.64 & 7.52 & 2.69 & 18.09 & 4.54 \\
\hline Annual runoff $\left(10^{9} \mathrm{~m}^{3}\right)$ & 73.3 & 12.6 & 28.8 & 62.8 & 61.1 & 928.0 & 336.0 \\
\hline Population ( $10^{8}$ persons $)$ & 0.51 & 0.34 & 1.1 & 0.92 & 1.42 & 3.79 & 0.82 \\
\hline Cultivated land $\left(10^{6} \mathrm{hm}^{2}\right)$ & 10.47 & 4.40 & 11.33 & 12.13 & 12.33 & 23.47 & 4.67 \\
\hline Total yield of grain production $\left(10^{6} \mathrm{t}\right)$ & 29.21 & 17.71 & 37.31 & 27.58 & 61.22 & 143.34 & 21.96 \\
\hline
\end{tabular}

Source Ministry of Water Resources (2014)

relative deficiency of precipitation. Thus commonly used drought indices rely on precipitation measurements only, such as the standardized precipitation index (SPI) and the percentage of precipitation anomalies $(\mathrm{Pa})$ (McKee et al. 1993). The length of precipitation record and the nature of the probability distribution of regional precipitation play an important role in calculating SPI. In arid areas such as

\footnotetext{
Calculate drought index $(\mathrm{Pa})$ at each $0.5^{\circ} \times 0.5^{\circ}$ grid using grid precipitation dataset (Sect. 3.1)

Determine drought duration $(D D)$, drought severity $(D S)$, drought intensity $(D I)$, and maximum severity of drought events based on the run theory method with three thresholds (Sect. 3.2)

Determine annual average drought frequency $(A D F)$, mean drought duration $(M D D)$,
mean drought severity $(M D S)$, mean drought intensity $(M D I)$, and incidence of
drought in different seasons $(D \mathrm{spr}, D$ sum, $D$ aut, $D$ win) for each grid. Analyze the
general spatial pattern and seasonal characteristics of drought in China (Sect. 3.3)

Determine the relative change of drought frequency $(R C D F)$ and drought duration $(R C D D)$, and the change of drought severity $(C D S)$ and drought intensity $(C D I)$. Analyze the temporal change of drought characteristics in 10 water resource regions (Sect. 3.3)
}

Fig. 2 A schematic diagram of the methodology adopted in this study
Northwest China, there are many zero precipitation days in a particular season. This may lead to large errors when simulating precipitation distributions in dry climates from small data samples. But $P a$ is one of the most straightforward indices with which to measure the precipitation deviation from its long-term mean and thus $P a$ was employed in this study. $P a$ is defined as:

$$
P a_{i j}=\frac{P_{i j}-\bar{P}_{j}}{\bar{P}_{j}}
$$

where $i$ is year (1961-2014), and $j$ indicates month (1-12). $P_{i j}(\mathrm{~mm})$ is the monthly precipitation for the month $j$ of year $i$, and $\bar{P}_{j}(\mathrm{~mm})$ is the monthly mean precipitation during the period 1961-2014.

\subsection{Drought Identification}

Run theory has been applied in some previous drought analyses (Sen 1976, 1980; Dracup et al. 1980; Loaiciga and Leipnik 1996). In this study, a series of drought events are identified by the run theory method with three thresholds. Taking monthly $\mathrm{Pa}$ as the drought index, drought event series in each grid are identified as follows:

(1) $R O$ is the threshold for pooling adjacent drought events; $R 1$ is the drought occurrence threshold; and $R 2$ is the threshold for removing minor drought events. We

Fig. 3 Identification of drought events based on the run theory method with three thresholds ( $R O$ is the drought pooling threshold; $R I$ is the drought occurrence threshold; and $R 2$ is the minor drought removing threshold)

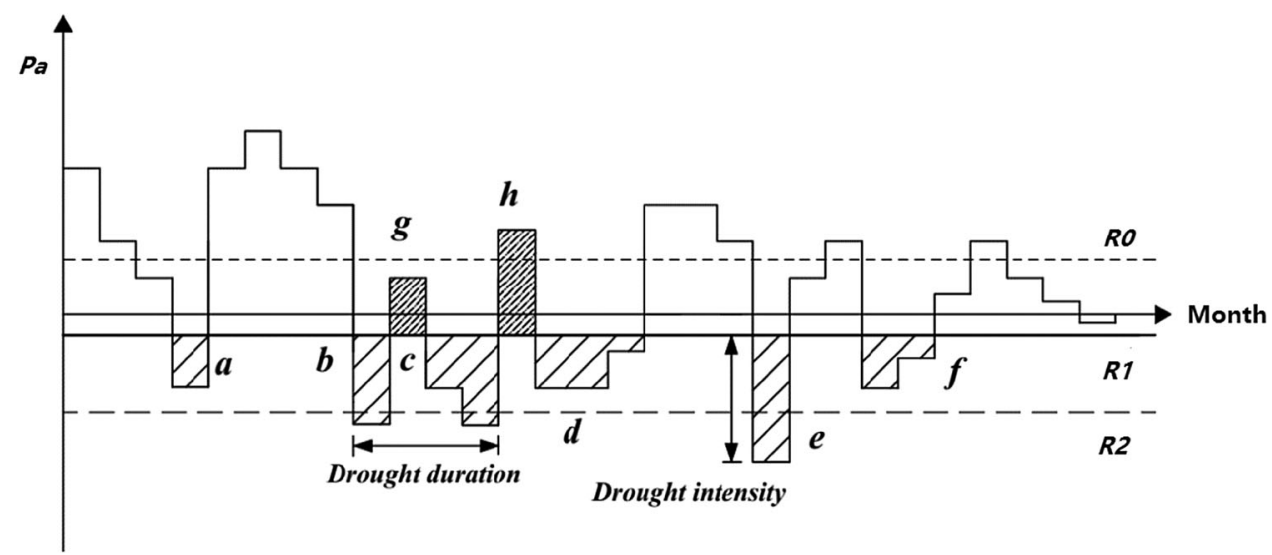


define that drought occurs when the value of the monthly drought index $P a$ falls below $R 1$. In Fig. 3, as an example, there are six drought event candidates (denoted as $a, b, c, d$, $e$, and $f$ ) after the preliminary screening using the threshold $R 1$.

(2) If the preliminarily identified drought event with one month duration shows a lower $P a$ value than $R 2$, this event is then treated as a minor drought and will be removed. In the example shown in Fig. 3, drought event $a$ will be removed from the drought candidate list. After removing the minor drought, there remain five drought event candidates $(b, c, d, e$, and $f)$.

(3) Two adjacent drought events are pooled if they are only separated for 1 month and the index value for the month in between falls below RO. As shown in Fig. 3, drought events $b$ and $c$ are pooled and four drought events $(b-c, d, e$, and $f)$ are finally identified.

$R O$ is set to $0.1, R 1$ is set to -0.4 , and $R 2$ is set to -0.65 in this study according to the recommendations of Classification of Meteorological Drought standard (China Meteorological Administration 2006) and previous studies (Yuan et al. 2013; Zhou et al. 2014; He 2015).

\subsection{Drought Event Statistics}

Once all the drought events have been identified from the monthly $\mathrm{Pa}$ series of each grid, a meteorological drought event can be characterized with the following indicators:

(1) Drought initiation time (DIT): the starting month of the rainfall shortage period, which indicates the beginning of a drought.

(2) Drought termination time (DTT): the month when rainfall shortage became sufficiently small so that drought conditions no longer persist.

(3) Drought duration $(D D)$ : the time period between the initiation $(D I T)$ and termination $(D T T)$ of a drought event (for example, $D D_{b-c}$ means the drought duration of $b-c$ in Fig. 3, where $D D_{b-}$ ${ }_{c}=D D_{b}+D D_{c}+1=4$ month).

(4) Drought severity $(D S)$ : indicates a cumulative precipitation deficiency of a drought with $P a$ below the given drought occurrence threshold during the duration $D D$ (for example, $D S_{b-c}$ means the drought severity of $b$-c, where $D S_{b-c}=D S_{b}+D S_{c}$ ).

(5) Drought intensity $(D I)$ : is the average value of precipitation deficiency of a drought, which is measured as the severity $D S$ divided by the duration $D D$ (for example, $D I_{b-c}=D S_{b-c} / D D_{b-c}$ ).

Annual average drought frequency $(A D F)$ was computed for each grid as the total number of the identified drought events during 1961-2014 divided by the length of the study period-54 years. Moreover, the mean drought duration $(M D D)$, mean drought severity $(M D S)$, and mean drought intensity $(M D I)$ of the identified drought events in 1961-2014 were also calculated for each grid. Maximum drought duration and maximum drought severity also were calculated to describe extreme drought characteristics.

The incidence of drought in different seasons was calculated for each grid to analyze the seasonal contribution to annual meteorological drought events in China. The incidence of seasonal drought is measured as the drought duration in each season (spring, summer, autumn, and winter) divided by the total drought duration. The incidence of spring drought (Dspr) shows the drought duration ratio in March, April, and May. Similarly, the incidences of summer drought (Dsum), autumn drought (Daut), and winter drought ( $D$ win) were calculated as the ratio in JuneAugust, September-November, and December-February, respectively.

In order to quantify the temporal change of drought characteristics, the relative changes of drought frequency $(R C D F)$ and drought duration $(R C D D)$ and the changes of drought severity $(C D S)$ and drought intensity (CDI) between 1961-1990 and 1991-2014 were analyzed. The division of these two periods was based on the noticeable change of precipitation in a major part of northern China around 1990 (He et al. 2014). The change was computed as the difference between the two periods (absolute mean value in 1991-2014 minus that in 1961-1990), while the relative change was further computed by dividing the difference with the value in 1961-1990.

\section{Results}

The analysis results of meteorological drought in China include the following parts: (1) general patterns of precipitation; (2) spatiotemporal variations of drought in China based on statistical analysis of the frequency, duration, severity, and intensity of all identified drought events; and (3) trend analysis of decadal variations of droughts in 10 water resource regions.

\subsection{General Patterns of Precipitation}

Deficiency of precipitation is the main factor responsible for regional drought. We first analyze the spatiotemporal variations of precipitation in China before characterizing drought dynamics. Figure $4 \mathrm{a}$ displays the spatial pattern of annual precipitation for the period of 1961-2014. The distribution of annual precipitation is extremely uneven in China, decreasing from southeast to northwest. In general, the average annual precipitation is about $630 \mathrm{~mm}$ over the entire country. In some regions, for example the Pearl River basin, the annual precipitation amount exceeds 
$1200 \mathrm{~mm}$, while it is generally less than $250 \mathrm{~mm}$ in northwest China. The $400 \mathrm{~mm}$ isohyet displayed on Fig. 4a shows an overall alignment with the northern boundary of the summer monsoon-dominant area in China, which starts from the Songhua River in Northeast China, extends southwesterly across central China and ends in the Southwest region. Based on the $400 \mathrm{~mm}$ isohyet, China is divided into the southeast humid region and northwest arid region. Figure $4 \mathrm{~b}$ presents the precipitation variation ratio (calculated as the maximum annual precipitation divided by the minimum annual precipitation) throughout China for
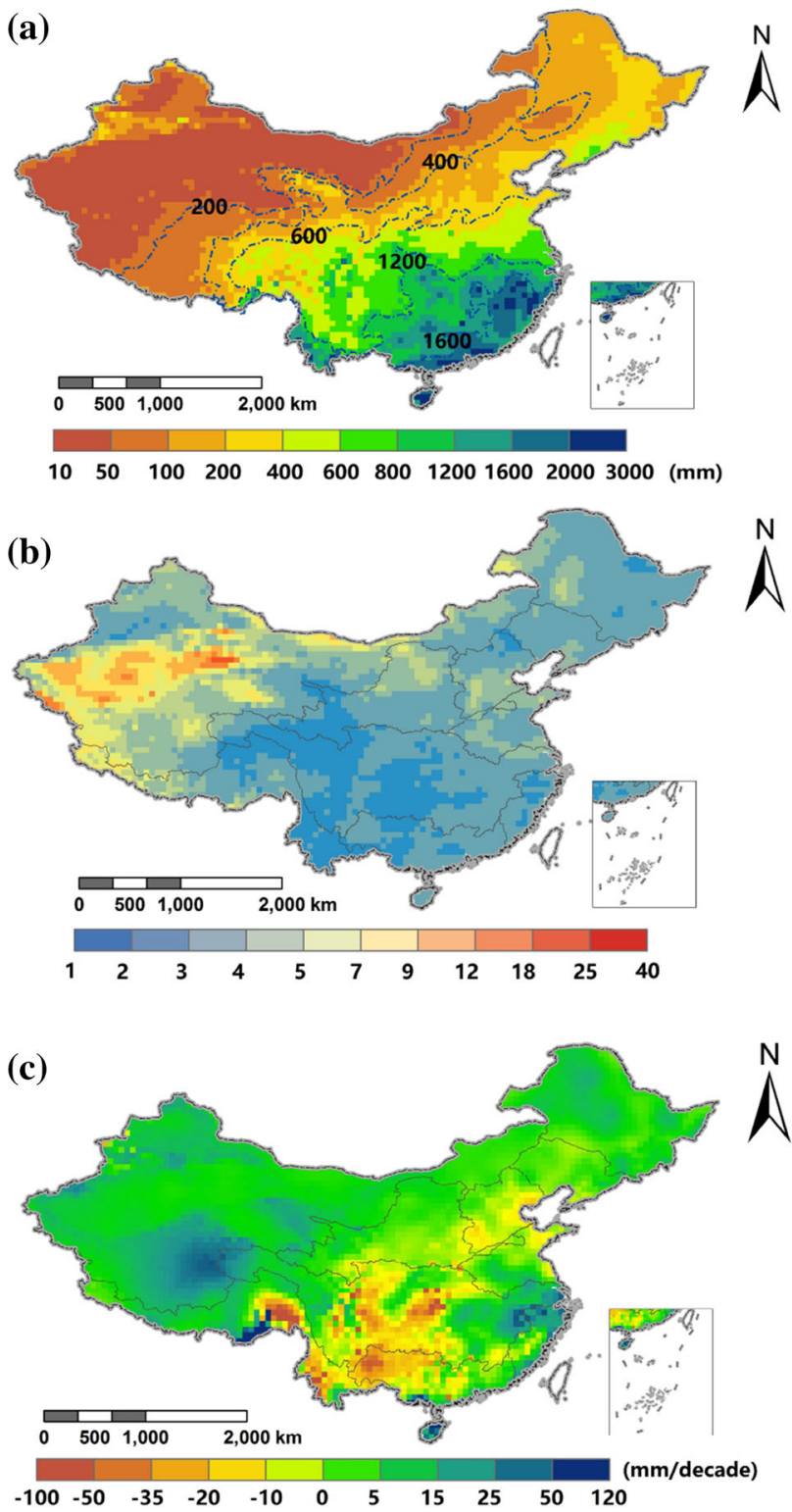

Fig. 4 Spatial distribution of precipitation related statistics in China: a average annual precipitation distribution (the dashed blue lines represent precipitation isohyets), $\mathbf{b}$ precipitation variation ratio (calculated as the maximum annual precipitation divided by the minimum annual precipitation during 1961-2014); c Linear trend of annual precipitation change (mm/decade) during 1961-2014
1961-2014 and reflects the variations of annual precipitation. The variation ratio varies from 3 to 5 at the southern Haihe River basin, western Huaihe River basin, and northern Yellow River basin. Most of western China is prone to large precipitation variability $(>5)$, particularly in the Tarim River basin in northwest China $(>10)$. For the Yangtze River basin, the variation rate ranges from 1 to 4 , which suggests that interannual variation of precipitation tends to be small in humid southern China. Figure $4 \mathrm{c}$ displays the change trend of annual precipitation by least squares regression. The precipitation in Northwest China, Northeast China, and the Yangtze River delta reflects an increasing trend $(5-15 \mathrm{~mm} /$ decade), whereas the precipitation in the Haihe River basin, the middle and upper reaches of the Yangtze River basin, and Southwest China shows an obvious decreasing trend (10-35 mm/decade) during the past 54 years.

\subsection{Spatiotemporal Variations of Drought Events}

Based on the drought events sequence at each $0.5^{\circ} \times 0.5^{\circ}$ grid across China from 1961 to 2014, the spatial and seasonal variations of meteorological droughts in China are analyzed and presented as follows.

\subsubsection{Drought Identification Result}

Evaluation of the drought identification results for local areas is illustrated by taking Beijing as an example. Figure 5 shows the monthly $P a$ index values of Beijing. It can be inferred that the variation range of $P a$ is between -1 and 6 , which reflects great variability of precipitation in this region.

By employing the run theory method based on the drought index $P a$, we can quantitatively measure every drought event from 1961 to 2014 in each grid. Table 2 summarizes the identified major drought events with a duration exceeding 3 months in Beijing. The recorded historical drought events in Beijing from various sources (Xie 2005) are also listed in Table 2.

\subsubsection{Spatial Variation of Droughts}

Figure 6a-d shows the spatial distribution of the annual average drought frequency $(A D F)$, mean drought duration $(M D D)$, mean drought severity $(M D S)$, and mean drought intensity $(M D I)$ in China during 1961-2014. There is a relatively high spatial correlation among the maps of various drought related characteristics. Collectively, the result shows that there are five evident drought-prone regions in China: the Huang-Huai-Hai Plain drought region, the Northeast China drought region (for example around the Liaohe River basin), the Southwest China drought region 
Fig. 5 Monthly $P a$ at the Beijing region (1961-2014)

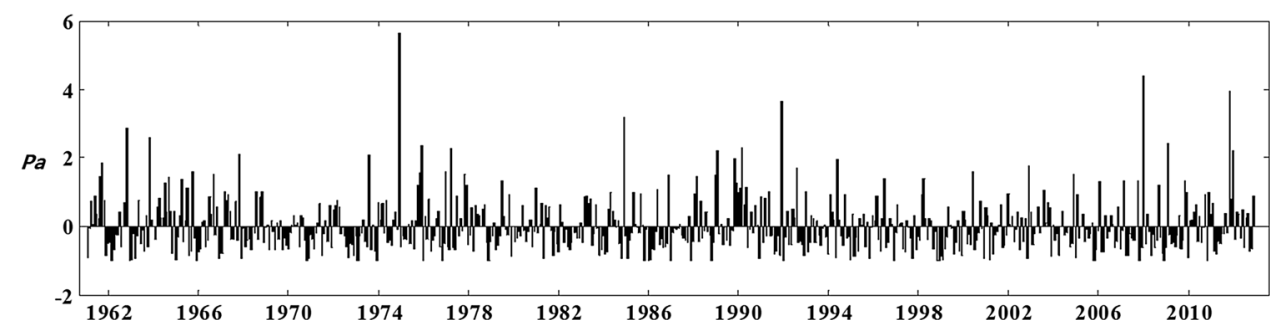

Table 2 Identification results of major drought events in Beijing region in 1961-2014 (DD > 3 months)

\begin{tabular}{llllll}
\hline $\begin{array}{l}\text { Drought initiation } \\
\text { time (year-month) }\end{array}$ & $\begin{array}{l}\text { Drought termination } \\
\text { time (year-month) }\end{array}$ & $\begin{array}{l}\text { Drought duration } \\
\text { (month) }\end{array}$ & $\begin{array}{l}\text { Drought } \\
\text { severity }\end{array}$ & $\begin{array}{l}\text { Drought } \\
\text { intensity }\end{array}$ & $\begin{array}{l}\text { Recorded historical drought } \\
\text { event (year-month) }\end{array}$ \\
\hline $1962-8$ & $1963-2$ & 7 & -1.942 & -0.277 & $1962-7$ to 1963-1 \\
$1964-11$ & $1965-3$ & 5 & -2.189 & -0.438 & $1965-1$ to 1965-6 \\
$1966-9$ & $1966-12$ & 4 & -0.865 & -0.216 & $1966-10$ to 1966-12 \\
$1967-11$ & $1968-6$ & 8 & -1.622 & -0.203 & $1967-12$ to $1968-6$ \\
$1972-2$ & $1972-6$ & 5 & -1.188 & -0.238 & $1972-3$ to 1972-8 \\
$1977-1$ & $1977-4$ & 4 & -1.201 & -0.300 & $1976-12$ to $1977-4$ \\
$1982-1$ & $1982-5$ & 5 & -1.494 & -0.299 & $1982-1$ to 1982-4 \\
$1982-9$ & $1983-1$ & 5 & -1.094 & -0.219 & $1982-9$ to 1983-4 \\
$1985-10$ & $1986-1$ & 4 & -1.044 & -0.261 & $1985-10$ to 1986-1 \\
$1992-10$ & $1993-2$ & 5 & -1.483 & -0.297 & $1992-11$ to 1993-6 \\
$1998-11$ & $1999-7$ & 9 & -2.255 & -0.251 & $1998-8$ to 1999-7 \\
$2001-2$ & $2001-5$ & 4 & -0.740 & -0.185 & $2001-3$ to 2001-6 \\
$2005-9$ & $2006-4$ & 8 & -2.520 & -0.315 & $2005-10$ to 2006-2 \\
$2010-11$ & $2011-1$ & 4 & -1.469 & -0.490 & $2010-11$ to 2011-2 \\
$2013-10$ & $2014-3$ & 6 & -2.047 & -0.341 & $2013-11$ to 2014-5 \\
\hline
\end{tabular}

(mainly in Yunnan Province), the South China coastal drought region (mainly in Guangdong and part of Fujian Provinces), and the Northwest China drought region (not including northern Xinjiang). In the Northwest China drought region, the $M D D$ of the Tarim River basin exceeds 3.8 months, while $M D S$ is less than -1.4 and $M D I$ is less than -0.4 , and thus this region is considered to be the area that suffers the most serious drought risk in China according to many statistics. As statistical indicators of drought, the $A D F, M D D, M D S$, and $M D I$ of the HuangHuai-Hai Plain drought region range from 1.2 to 1.8 times annually, 2.2 to 3.4 months, -0.8 to -1.2 , and -0.3 to -0.45 , respectively. Figure $6 \mathrm{e}$, f display the spatial distribution of statistics for extreme events, considering the maximum duration and the maximum severity of droughts in China. The overall results show that the highest drought duration and severity are found in the Tarim River basin and the western Tibet Plateau, followed by the HuangHuai-Hai Plain, Southwest China, and Northeast China. However, the maximum values of drought duration and severity in the South China coastal drought region seem relatively low, which indicates a relatively small risk of extreme drought in this region.

\subsubsection{Seasonal Variation of Droughts}

Figure 7 shows the seasonal pattern of drought events from 1961 to 2014 in China, which are characterized by the drought duration ratio presented in the previous section. The result indicates there are evident spatial differences among the drought duration ratio maps, which reflects the variations of seasonal contribution to regional droughts. Spring drought mainly takes place in northern China (for example Northeast China) and Southwest China, where the incidence of spring drought accounts for 20 to $35 \%$ of the total. In the summer, drought is concentrated mainly in the middle and lower reaches of the Yangtze River basin, with the incidence ranging from 20 to $40 \%$. In the autumn, most drought events occur in the lower Yangtze River area as well as along Southeast China coast, with the incidence varying from 35 to $55 \%$. Winter droughts mainly occur in the upper reaches of the Yangtze River and the Yellow River basins, the Liaohe River basin, and Southwest China, with the drought duration ratio varying from 45 to $65 \%$. Clearly, most of the contributions to annual drought events in China were from the winter season. 
Fig. 6 Spatial distribution of drought characteristics in China during 1961-2014: a $A D F$ average annual drought frequency (times per year); b $M D D$ mean drought duration (months); c $M D S$ mean drought severity; d $M D I$ mean drought intensity; e Maximum drought duration (months); f Maximum drought severity
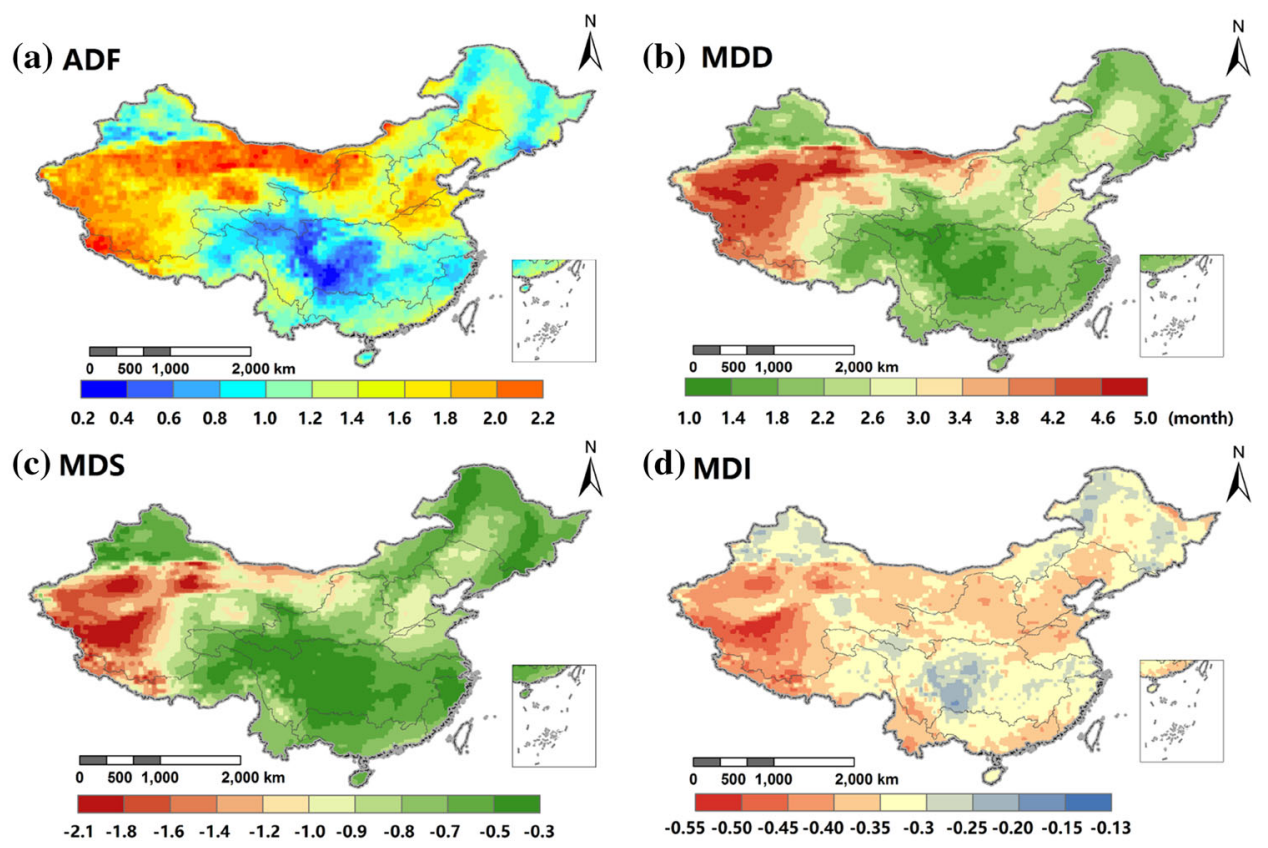

(e) Maximum drought duration

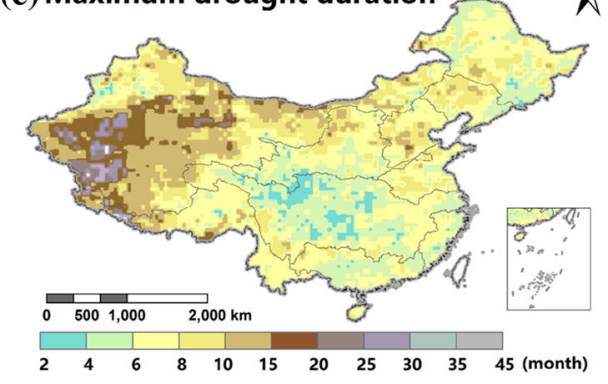

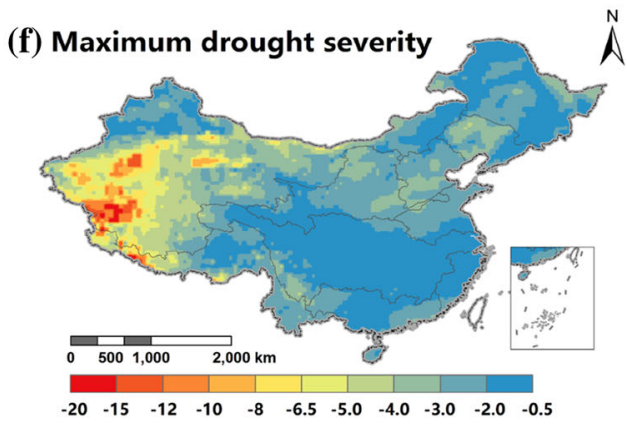

\subsection{Decadal Variation of Droughts}

Long-term change in the pattern of drought events in China was first analyzed by comparing the drought event statistics in two time periods: 1961-1990 and 1991-2014. Figure 8 shows the relative changes of drought frequency $(R C D F)$ and drought duration $(R C D D)$, and the changes of drought severity $(C D S)$ and drought intensity $(C D I)$ between the two time periods. Overall, the majority of China has experienced an increasing trend of both drought frequency and drought intensity for the period 1991-2014, while drought duration slightly decreased (by $0-25 \%$ ) for most areas of China. Specifically, the increase of drought frequency is evident in the Huang-Huai-Hai Plain, the Liaohe River basin, the middle and lower reaches of the Yangtze River basin, and the upper reaches of the Pearl River basin. The spatial pattern of drought severity is complicated and there is a lack of general trend over the whole country.

To better understand the decadal variability of regional droughts, we calculated the drought event statistics of the 10 major water resource regions in five consecutive time periods: 1961-1970, 1971-1980, 1981-1990, 1991-2000, and 2001-2010. Figures 9, 10, 11 and 12 show the $A D F$, $M D D, M D S$, and $M D I$ of the 10 water resource regions in the five time periods, respectively. Generally speaking, according to the four diagnostic statistics, river basins in Northwest and Southwest China always suffer more serious droughts than other regions. The Yangtze River basin experiences the lowest drought level, which is consistent with our spatial variation of drought analysis. Obviously, the most serious drought period is the first decade (1961-1970). Figure 9 shows that among the 10 water resource regions, most of them have undergone an increase of $A D F$, especially in the Liaohe, Haihe, and Yellow River basins. Figures 10 and 11 show that $M D D$ shortened and $M D S$ weakened obviously after the 1961 s. For rivers in the northwest, there is a gradual decreasing trend of both $M D D$ and $M D S$ during all five decades. Figure 12 shows that MDI exhibited no clear trend. Specifically, in the Haihe River basin, the $A D F$ and $M D I$ show an increasing trend from 1961 to 2010. The drought intensity of the Yellow River basin $(M D I=0.31)$ is higher than that of the Yangtze River basin $(M D I=0.26)$. But these two regions generally show no obvious trend in change of intensity. 
Fig. 7 Incidence of drought (by drought duration ratio) in different seasons in China during 1961-2014: a spring;

b summer; c autumn; d winter
Fig. 8 Temporal change of drought characteristics between 1961-1990 and 1991-2014: a Relative change of drought frequency $(C R D F)$. b Relative change of mean drought duration $(R C D D)$. $\mathbf{c}$ Change of mean drought severity $(C R S)$. d Change of mean drought intensity $(C D I)$. The relative change was computed as the difference between the two periods (absolute mean value in 1991-2014 minus that in 1961-1990) divided by the absolute value in 1961-1990

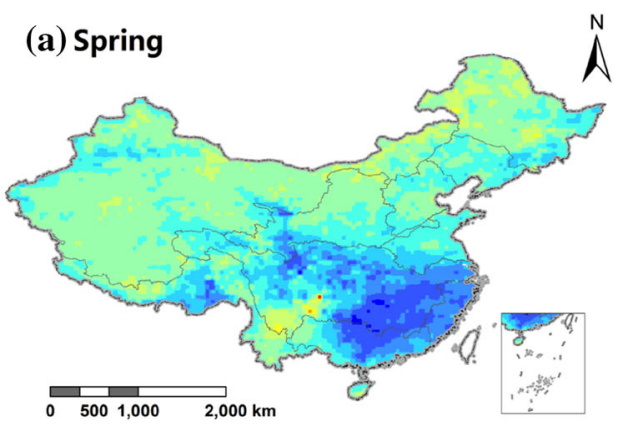

(b) Summer

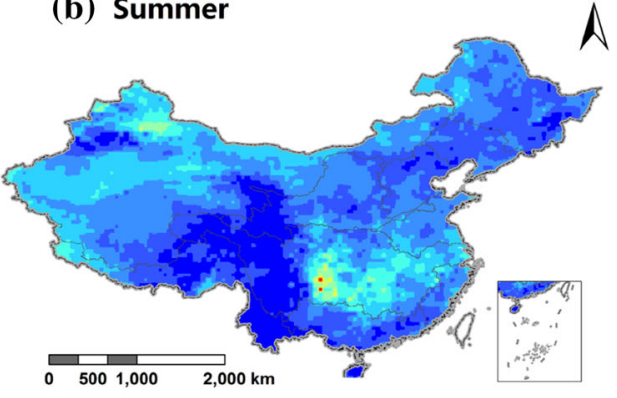

(c) Autumn

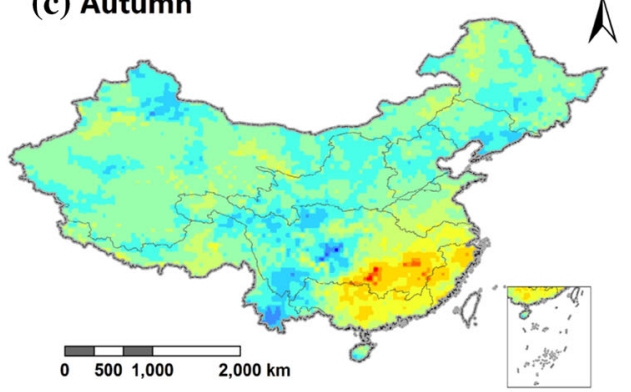

(d) Winter

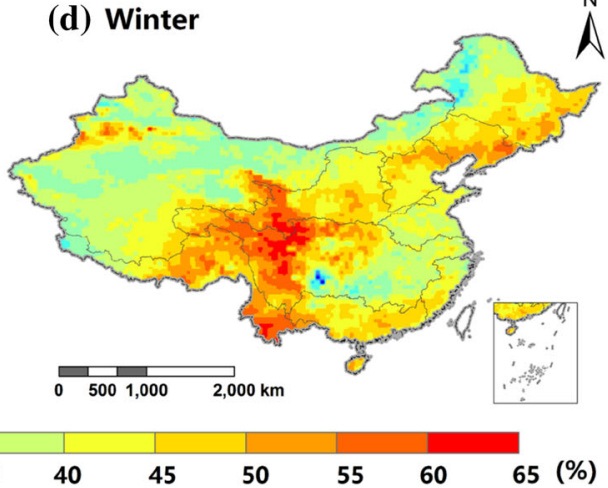

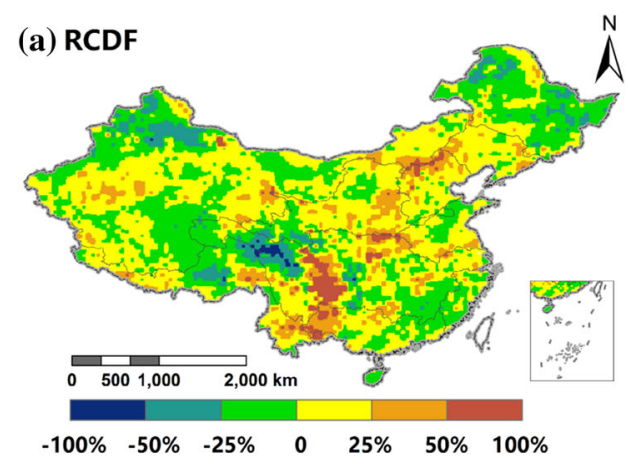

(c) $\operatorname{CDS}$

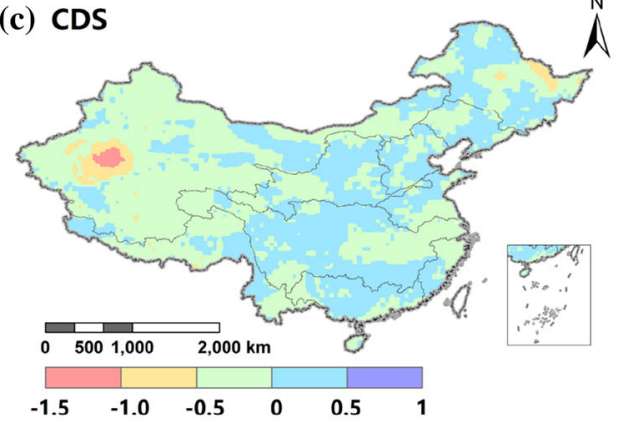

(b) RCDD

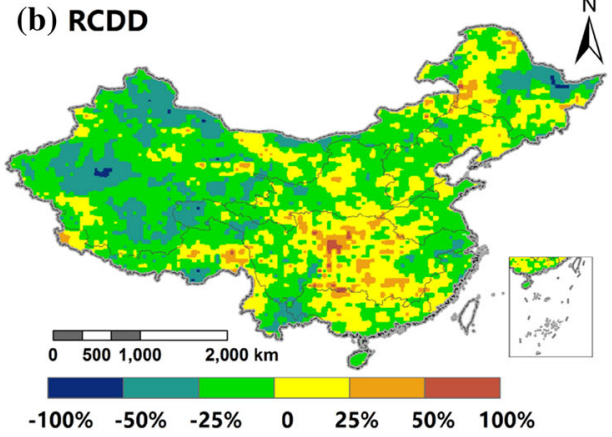

(d) CDI

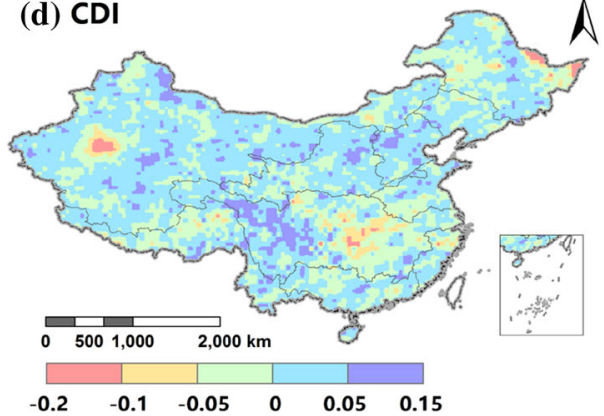

\section{Discussion}

Precipitation distribution in China is greatly influenced by elevation, latitude, and distance from the sea (Ding 2008). For the last 54 years, precipitation in the Haihe River basin, the middle and lower reaches of the Yellow River basin, and Southwest China has decreased, a development that suggests a drying tendency. In contrast, the precipitation of Northwest China shows an upward trend, which indicates at least a temporary wetter tendency in this region. Those results are consistent with previous studies (Yu et al. 2014; Xu et al. 2015). With a diverse pattern of precipitation in China, it is expected that the variation of historical droughts at the country level should be 
Fig. 9 Decadal variation of the annual average drought frequency $(A D F)$ in each water resource region: a Songhua River; b Liaohe River; c rivers in Northwest; d Haihe River; e Yellow River; f Yangtze River; $\mathbf{g}$ Huaihe River; $\mathbf{h}$ rivers in southeast; $\mathbf{i}$ rivers in southwest; j Pearl River

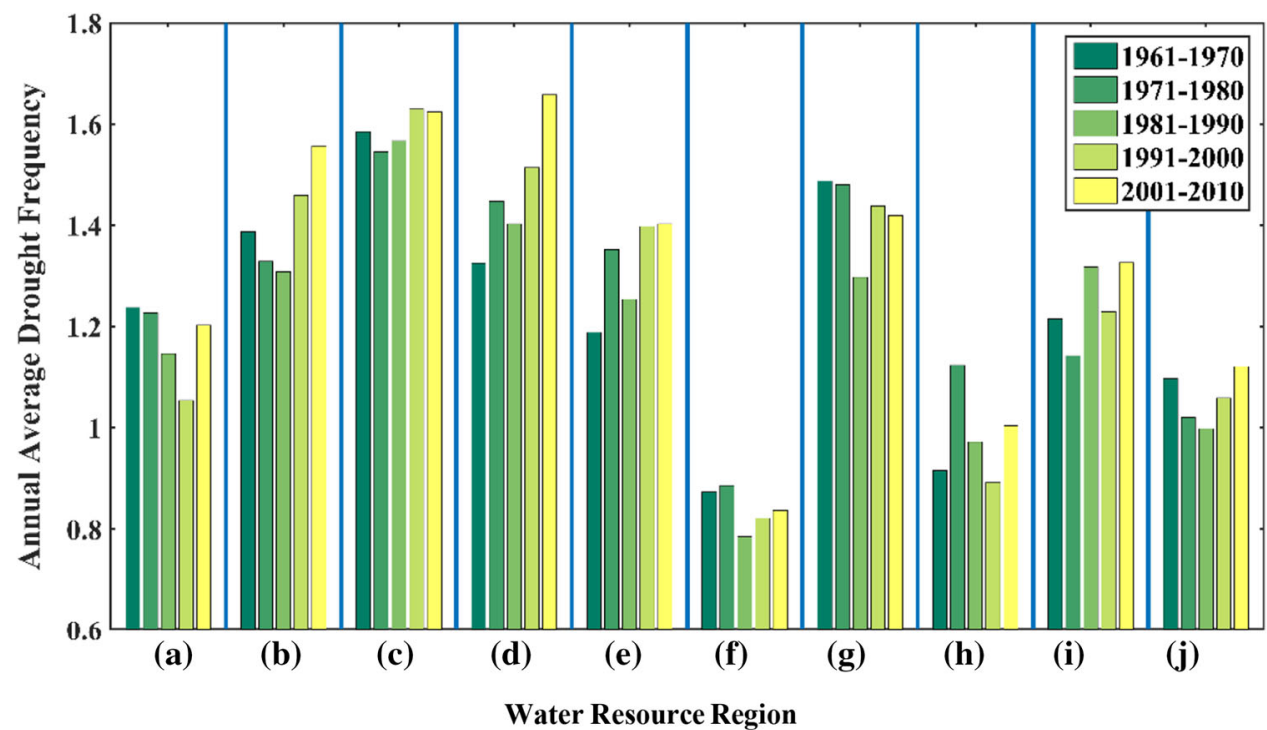

Fig. 10 Decadal variation of the mean drought duration $(M D D)$ in each water resource region: a Songhua River; b Liaohe River; c rivers in northwest; d Haihe River; e Yellow River; f Yangtze River; $\mathbf{g}$ Huaihe River; $\mathbf{h}$ rivers in southeast; $\mathbf{i}$ Rivers in Southwest; j Pearl River

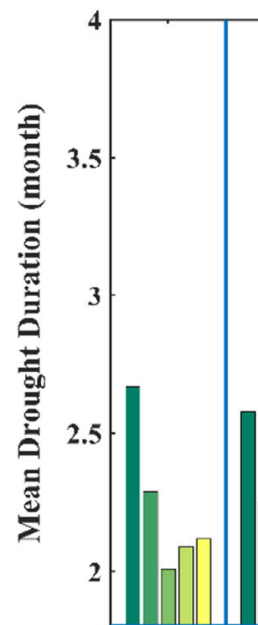

(a) (b)

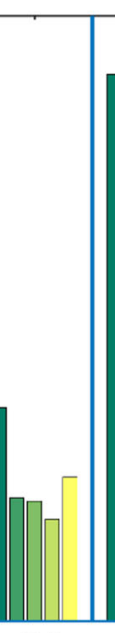

) (c)

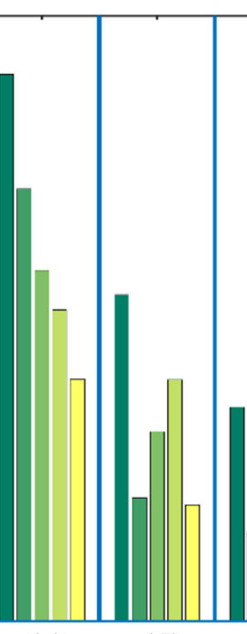

(d)

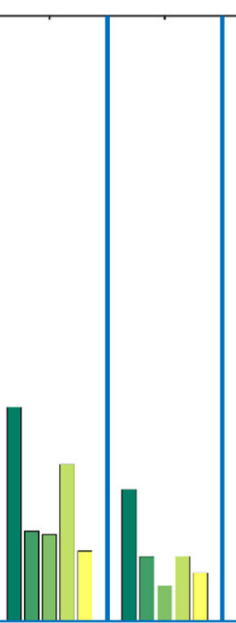

(e) (f)

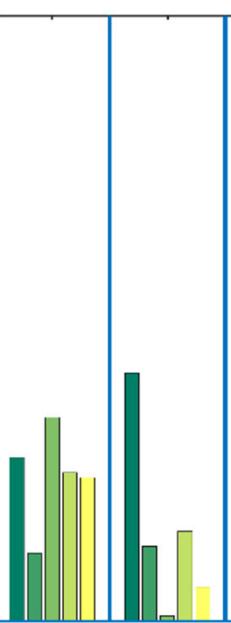

(g) (h)

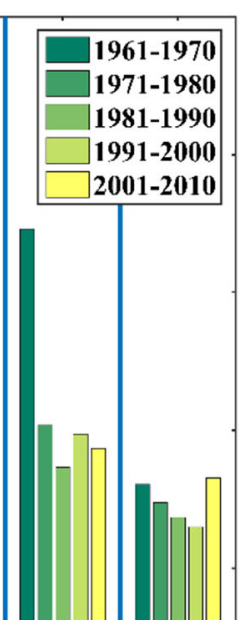

(i)

(j)

Water Resource Region

complicated as well. Comparing the identified drought events with the historical records in the 54 years of study data (Table 2), it is found that the run theory method identifies typical drought events reasonably according to their initiation and termination time, which shows better performance as compared to traditional drought index classification method (He 2015).

The five most drought-prone regions (Huang-Huai-Hai Plain, Northeast China, Southwest China, Southern China costal region, and Northwest China) identified by our $0.5^{\circ} \times 0.5^{\circ}$ grid level precipitation data analysis and the multi-threshold drought identification method reflect the basic pattern of the spatial distribution of meteorological droughts in China. These five regions should be the key areas in which China fights against drought disaster and develops improved coping strategies. The Huang-Huai-Hai Plain drought region, which is a heavily populated and rapidly developing economic region as well as the main grain production base in China (Table 1), may suffer much greater economic loss from the same degree of drought threat to which the other four comparable drought-prone regions are exposed. Judged by various drought-related statistics ( $A D F, M D D, M D S$, and $M D I)$, Northeast China and Southwest China drought regions both indicate a relatively high degree of drought frequency and intensity. In contrast, droughts in Southern China coastal region impact a small area, have a short duration (from 1.8 to 3.0 months), and are relatively high intensity events (between -0.30 and -0.45$)$. Overall, the $A D F$ of the Yangtze River basin ranges from 0.2 to 1.0 occurrences per year, 
Fig. 11 Decadal variation of the mean drought severity $(M D S)$ in each water resource region: a Songhua River; b Liaohe River; c rivers in northwest; d Haihe River; e Yellow River; f Yangtze River; $\mathbf{g}$ Huaihe River; $\mathbf{h}$ rivers in southeast; $\mathbf{i}$ rivers in southwest; j Pearl River
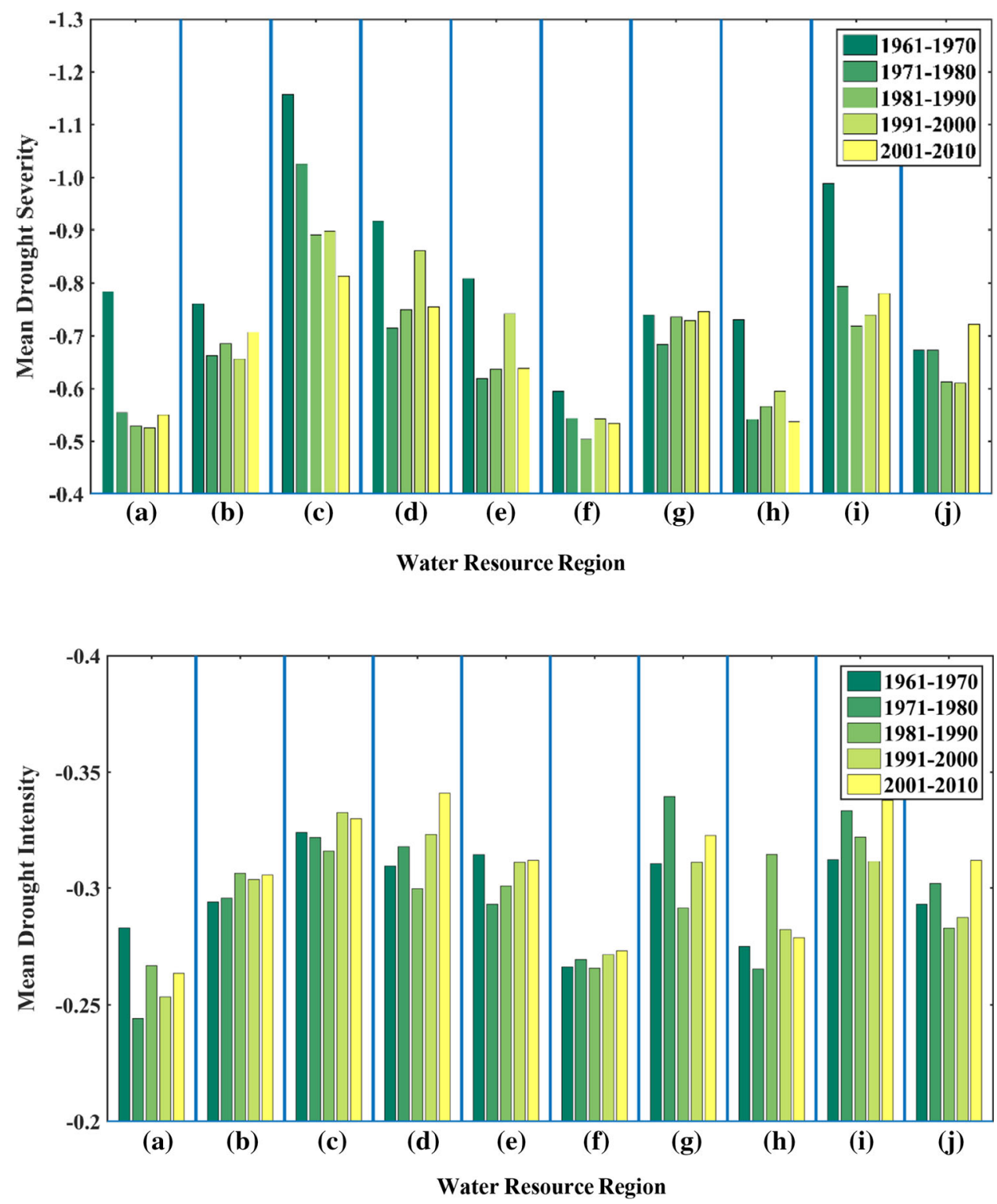

Fig. 12 Decadal variation of the mean drought intensity $(M D I)$ in each water resource region: a Songhua River; b Liaohe River; c rivers in northwest; d Haihe River; e Yellow River; f Yangtze River; $\mathbf{g}$ Huaihe River; $\mathbf{h}$ rivers in southeast; $\mathbf{i}$ rivers in southwest; j Pearl River and the $M D I$ of the region varies from -0.13 to -0.3 . This indicates that the Yangtze River basin is the area with smallest drought risk in China. Temporal variations of drought for the five main drought-prone regions indicate that the Huang-Huai-Hai Plain region has been mainly dominated by spring and winter droughts, which exert a significant impact on regional agriculture. Northwest China has mainly suffered from spring, autumn, and winter droughts, while drought always hit Northeast China consecutively in the winter and spring, with a relatively low contribution (less than $20 \%$ ) from the summer. Southwest China generally experienced drought in the winter and spring, which imposes a huge threat to agriculture and human and livestock drinking water. Southern China coastal region was often struck by drought in autumn and winter, but only occasionally by spring and summer droughts. Although the Yangtze River basin presents the smallest drought risk at an annual scale, the seasonal analysis reveals that the incidence of summer drought in this region is higher than other regions. China is located in the East Asian Monsoon region; this sets the pattern for seasonal meteorological drought in China because the region's large interannual variations in drought intensity and timing are controlled by the rhythm and activity level of the monsoon (Zhang and Zhou 2015). North China, for example, usually warms up rapidly in the spring and this temperature increase leads to spring drought due to reduced precipitation, strong winds, and a large amount of evaporation. As the Pacific Subtropical High moves northward in the summer, a rain belt center is formed north of the 
Yellow River basin, which controls the ending time of the spring drought (Zhai and Feng 2008).

Analysis of the decadal variation of meteorological droughts in China indicates that northern China (including the Songhua River, Liaohe River, Haihe River, and Yellow River basins as well as rivers in Northwest China) presents an increasing trend of drought frequency since 1961. In southern China, for instance in the Huaihe River, Pearl River, and Yangtze River basins, there are no evident trends of change in drought frequency. River basins in Southwest China show relatively high values of all statistics ( $A D F, M D D, M D S$, and $M D I$ ) in 2001-2010, which suggest a significant drought risk increase in recent years. An overall analysis of population, agricultural land, and grain output distribution situations (Table 1) indicates that the Haihe River basin is subject to the highest drought risk, closely followed by the Yellow River basin in its middle and lower reaches, together with the Huaihe River basin and the rivers of Southwest China. In contrast, the Yangtze River basin and most rivers in Southeast China had a relatively low drought risk. At the same time, Northwest China became the top drought region in terms of meteorological drought frequency, duration, and severity. This region has a relatively small agricultural drought disaster risk owing to an oasis irrigation cultivation system that does not rely heavily on precipitation. The Huang-HuaiHai River basin had a relatively high drought frequency and intensity, which constitutes a significant potential impact on regional social and economic development. Therefore the Huang-Huai-Hai River basin is the region most threatened by high drought disaster risks.

\section{Conclusion}

This article utilizes the multi-threshold run theory method to calculate drought events sequence at each $0.5^{\circ} \times 0.5^{\circ}$ grid across China from 1961 to 2014. Drought spatiotemporal variations have been investigated based on statistical analysis of the frequency, duration, severity, and intensity of all identifiable drought events. Taking 10 water resource regions for regional scale analysis, this study also evaluated the drought variations for these regions over the past five decades. Findings are summarized as follows:

(1) In the recent 54 years, the precipitation of the Haihe River basin, the middle and lower reaches of the Yellow River basin, and Southwest China has decreased, suggesting a drying tendency over these regions. In contrast, precipitation of the Northwest region shows slight upward trend, which means a wetting tendency there.
(2) Five evident meteorological drought-prone regions are identified by the multi-threshold run theory method, namely the Huang-Huai-Hai Plain drought region, Northeast China drought region (mainly the Liaohe River basin), Southwest China drought region (mainly in Yunnan Province), Southern China costal drought region (mainly in Guangdong and Fujian Provinces), and Northwest China drought region (not including northern Xinjiang). The Yangtze River basin tends to have relatively low drought risk with low drought frequency and intensity. Those five regions reflect the basic pattern of the spatial distribution of meteorological droughts in China, where should be the key areas for China to fight against drought disaster.

(3) Spring drought mainly took place in northern China and Southwest China, while summer drought occurred more frequently in the middle and lower reaches of the Yangtze River basin. In the autumn, most drought events were located in the lower Yangtze River basin, as well as along Southeast China coast. Winter droughts mainly occurred in the upper reaches of the Yangtze River and Yellow River basins, Liaohe River basin, and Southwest China. Overall, most contributions to annual drought events in China were from the winter season.

(4) The most serious drought period during the past five decades in China was 1961-1970. Most of the water resource regions have undergone an increase of drought frequency, especially in the Liaohe River, Haihe River, and Yellow River basins, but drought duration and severity show clear decrease after the 1960s. As for drought intensity, decadal variations have no consistent trend.

(5) Northwest China was the most severe drought region nationwide in terms of meteorological drought frequency, duration, and severity. In contrast, the Huang-Huai-Hai River basin had a relatively high drought frequency and intensity, which have significant implications on regional social and economic development.

However, few limitations remain in the current study. The meteorological drought identification result cannot directly reflect the variation of water availability, which is of great concern to water resource management. In addition, because the multi-threshold value of the run theory method relies on empirical study, further research is needed in this area.

Acknowledgments Funding for this research was provided by the National Basic Research Program of China (2012CB955403), the National Natural Science Foundation of China (41425002 and the National Youth Top-notch Talent Support Program in China). 
Open Access This article is distributed under the terms of the Creative Commons Attribution 4.0 International License (http://crea tivecommons.org/licenses/by/4.0/), which permits unrestricted use, distribution, and reproduction in any medium, provided you give appropriate credit to the original author(s) and the source, provide a link to the Creative Commons license, and indicate if changes were made.

\section{References}

Barriopedro, D., C.M. Gouveia, and R.M. Trigo. 2012. The 2009/2010 drought in China: Possible causes and impacts on vegetation. Journal of Hydrometeorology 13(4): 1251-1267.

Bayat, B., M. Nasseri, and B. Zahraie. 2015. Identification of longterm annual pattern of meteorological drought based on spatiotemporal methods: Evaluation of different geostatistical approaches. Natural Hazards 76(1): 515-541.

Bonacci, O. 1993. Hydrological identification of drought. Hydrological Processes 7(3): 249-262.

Burke, E.J., and S.J. Brown. 2010. Regional drought over the UK and changes in the future. Journal of Hydrology 394(3-4): 471-485.

Carrão, H., A. Singleton, and G. Naumann. 2014. An optimized system for the classification of meteorological drought intensity with applications in drought frequency analysis. Journal of Applied Meteorology and Climatology 53(8): 1943-1960.

Chang, T.J., and X.A. Kleopa. 1991. A proposed method for drought monitoring. Jawra Journal of the American Water Resources Association 27(2): 275-281.

China Meteorological Administration. 2006. Classification of meteorological drought. Beijing: Standards Press of China (in Chinese).

Dash, B.K., M. Rafiuddin, F. Khanam, and M.N. Islam. 2012. Characteristics of meteorological drought in Bangladesh. Natural Hazards 64(2): 1461-1474.

Ding, Y.H. 2008. China meteorological disaster dictionary (Comprehensive volume). Beijing: China Meteorological Press (in Chinese).

Dracup, J.A., K.L. Lee, and E.G. Paulson. 1980. On the definition of droughts. Water Resources Research 16(2): 297-302.

Estrela, M.J., D. Peñarrocha, and M. Millán. 2000. Multi-annual drought episodes in the Mediterranean (Valencia region) from 1950 to 1996. A spatio-temporal analysis. International Journal of Climatology 20(13): 1599-1618.

Fleig, A.K., L.M. Tallaksen, H. Hisdal, and S. Demuth. 2006. A global evaluation of streamflow drought characteristics. Hydrology and Earth System Sciences 10(4): 535-552.

Gibbs, W.J. 1975. Drought, its definition, delineation and effects. In Drought: Lectures presented at the 26th session of the WMO. Report No. 5, 3-30. Geneva: World Meteorological Organization.

Hallack-Alegria, M.M., and D.W. Watkins. 2007. Annual and warm season drought intensity-duration-frequency analysis for sonora, Mexico. Journal of Climate 20(9): 1897-1909.

He, J. 2015. The spatiotemporal multiscale drought identification and evaluation under climate change in Huang-Huai-Hai River Basin. Ph.D. dissertation, Beijing Normal University, Beijing, China.

He, J., X.H. Yang, J.Q. Li, J.L. Jin, Y.M. Wei, and X.J. Chen. 2014. Spatiotemporal variation of meteorological droughts based on the daily comprehensive drought index in the Haihe River basin, China. Nature Hazards 75: S199-S217.

Liu, C.M, and S.F. Zhang. 2002. Drying up of the Yellow River: Its impacts and counter-measures. Mitigation and Adaptation Strategies for Global Change 7(3): 203-214.
Lloyd-Hughes, B., and M.A. Saunders. 2002. A drought climatology for Europe. International Journal of Climatology 22(13): 1571-1592.

Loaiciga, H.A., and R.B. Leipnik. 1996. Stochastic renewal model of low-flow streamflow sequences. Stochastic Hydrology and Hydraulics 10(1): 65-85.

McKee, T.B., N.J. Doeskin, and J. Kleist. 1993. The relationship of drought frequency and duration to time scales. In Proceedings of the eighth conference on applied climatology, Anaheim, CA: American Meteorological Society, 179-184.

Ministry of Water Resources. 2014. China water statistical yearbook 2013. Beijing: China Water and Power Press (in Chinese).

Mishra, A.K., and V.P. Singh. 2010. A review of drought concepts. Journal of Hydrology 391(1-2): 202-216.

Nandintsetseg, B., and M. Shinoda. 2012. Assessment of drought frequency, duration, and severity and its impact on pasture production in Mongolia. Natural Hazards 66(2): 995-1008.

Oh, S.B., H.R. Byun, and D.W. Kim. 2014. Spatiotemporal characteristics of regional drought occurrence in East Asia. Theoretical and Applied Climatology 117(1-2): 89-101.

Oladipo, E.O. 1985. A comparative performance analysis of three meteorological drought indices. Journal of Climatology 5(6): $655-664$.

Qian, W., and Y.L. Zhu. 2001. Climate change in China from 1880 to 1998 and its impact on the environmental condition. Climatic Change 50(4): 419-444.

Santos, M.A. 1983. Regional droughts: A stochastic characterization. Journal of Hydrology 66(1-4): 183-211.

Sen, Z. 1976. Wet and dry periods for annual flow series. Journal of the Hydraulics Division 102(10): 1503-1514.

Sen, Z. 1980. Statistical analysis of hydrologic critical droughts. Journal of the Hydraulics Division 106(1): 99-115.

Shen, C.M., W.C. Wang, Z.X. Hao, and W. Gong. 2007. Exceptional drought events over eastern China during the last five centuries. Climatic Change 85(3): 453-471.

Sung, J.H, and E.S. Chung. 2014. Development of streamflow drought severity-duration-frequency curves using the threshold level method. Hydrology and Earth System Sciences 18(9): 3341-3351.

Wang, A.H., D.P. Lettenmaier, and J. Sheffield. 2011. Soil moisture drought in China, 1950-2006. Journal of Climate 24(13): 3257-3271.

Wang, W., Y. Zhu, R.G. Xu, and J.T. Liu. 2014. Drought severity change in China during 1961-2012 indicated by SPI and SPEI. Natural Hazards 75(3): 2437-2451.

Wilhite, D.A., and M.H. Glantz. 1985. Understanding the drought phenomenon: The role of definitions. Water International 10(3): $111-120$.

Wu, J., and X.J. Gao. 2013. A gridded daily observation dataset over China region and comparison with the other datasets. Chinese Journal of Geophysics 56(4): 1102-1111.

Wu, Z.Y., G.H. Lu, L. Wen, and C.A. Lin. 2011. Reconstructing and analyzing China's fifty-nine year (1951-2009) drought history using hydrological model simulation. Hydrology and Earth System Sciences 15(9): 2881-2894.

Xie, P. 2005. China meteorological disaster dictionary (Beijing volume). Beijng: China Meteorological Press (in Chinese).

Xu, K., D.W. Yang, H.B. Yang, L. Zhe, Y. Qin, and Y. Shen. 2015. Spatio-temporal variation of drought in China during 1961-2012: A climatic perspective. Journal of Hydrology 526: 253-264.

Yang, J., D.Y. Gong, W.S. Wang, M. Hu, and R. Mao. 2012. Extreme drought event of 2009/2010 over southwestern China. Meteorology and Atmospheric Physics 115(3-4): 173-184.

Yevjevich, V. 1967. An objective approach to definitions and investigations of continental hydrologic droughts. Ph.D. dissertation, Colorado State University, Boulder, CO, USA. 
Yu, M.X., Q.F. Li, M.J. Hayes, and M. Svoboda. 2014. Are droughts becoming more frequent or severe in China based on the standardized precipitation evapotranspiration index: 1951-2010. International Journal of Climatology 34(3): 545-558.

Yuan, X.C., Y.L. Zhou, J.L. Jin, and Y.M. Wei. 2013. Risk analysis for drought hazard in China: A case study in Huaibei Plain. Natural Hazards 67(2): 879-900.

Zelenhasić, E., and A. Salvai. 1987. A method of streamflow drought analysis. Water Resources Research 23(1): 156-168.

Zhai, L., and Q. Feng. 2008. Spatial and temporal pattern of precipitation and drought in Gansu Province, Northwest China. Natural Hazards 49(1): 1-24.
Zhang, L.X., and T.J. Zhou. 2015. Drought over East Asia: A review. Journal of Climate 28(8): 3375-3399.

Zhou, Y.L., P. Zhou, and J.L. Jin. 2014. Establishment of hydrological drought index based on sources of regional water supply and its application to drought frequency analysis for Kunming. Journal of Hydraulic Engineering 45(9):1038-1047 (in Chinese). 